\title{
LOS LIBROS ITALIANOS QUE NO ME DEJAN DORMIR \\ Paolo Pagliai*
}

Hablar de lo que sucede en un país y en su producción literaria e intelectual es algo difícil, un reto para la mente y el alma. Cuando este país se llama Italia, el reto se vuelve, además, desafío desesperado, porque la bota de Europa es tierra de escritores y los libros abundan, invaden las librerías y ocupan perentoriamente las repisas de nuestras bibliotecas, aunque a veces nadie los lea.

Entonces, éste se convierte en un viaje fantástico que, como todo viaje y toda fantasía, oculta insidias, pérfidas seducciones, amores irracionales, odios sin una razón verdadera. Como los amores.

Los libros que se quedan atrapados entre las portadas de los demás, como decía Elías Canetti, gritan venganza y nos asaltan como bandidos

* Universidad del Claustro de Sor Juana. indeseables, portadores de malas noticias, sedientos de respuestas que sólo nosotros podemos dar... De hecho, en los libros no hay respuestas, solamente preguntas difíciles, y por esta razón muchos libros resultan insoportables, ya que nos cuestionan, nos quitan la silla cuando sentimos que, finalmente, podemos sentarnos. "Los libros te mantienen de pie", decía un maestro mío de la universidad, y sólo ahora me doy cuenta de lo que quería decir, ahora que todos estos libros me miran, amenazantes, desde mi librero.

Yo no conocí a Valerio Verra. Era profesor de Historia de la Filosofía en la Universidad de Roma "La Sapienza", una de las mejores a nivel mundial en el área de humanidades. Verra murió en 2001, tenía apenas 73 años. Hegel se había convertido, a lo largo de su historia existencial 
y académica, en el centro de sus investigaciones. Entre sus contribuciones a los estudios hegelianos recordamos La filosofía di Hegel (Loescher 1979), y la traducción de "La scienza della logica" ("La ciencia de la lógica"), primera parte de la Enciclopedia delle scienze filosofiche in compendio, Utet, 1981.

A Valerio Verra, me lo encontré en una librería, como se encuentra a un hombre interesante o a una mujer bellísima y sin embargo hostil: altera. El libro, Su Hegel (Sobre Hegel), no se presentaba como un fiel compañero de cabecera, más bien me recordaba los años duros de la formación escolar, mi Croce y mi Gentile, mis cincos en filosofía.

En efecto, no es lo que se dice un libro de divulgación, y sin embargo el pensamiento de Hegel es tan poderoso y provocativo que una persona, cuando empieza, no puede dejar de leerlo.

$\mathrm{Su} \mathrm{Hegel}$ ofrece una rica selección de los escritos de argumento hegeliano publicados, en el transcurso de los años, por Valerio Verra, uno de los más expertos intérpretes del filósofo alemán. Moviéndose entre la historia de las ideas en general, el análisis del léxico y el reconocimiento filológico y lexicográfico de las fuentes, Verra nos restituye una preciosa contribución al conocimiento profundo del pensamiento de Hegel, desde la comparación con la filosofía antigua de Aristóteles y Plotino, hasta aquélla con los grandes protagonistas de su época (Goethe), pasando por la investigación sobre los temas centrales de la filosofía de la naturaleza y la estética: arte y vida, poesía y pintura. Su Hegel es una selección de 'lecturas' caracterizada por la severa puntualidad de la disertación y la más rigurosa fidelidad al dato textual, una obra que difícilmente será traducida al castellano y que, por esta sencilla razón, seguirá gritando en un idioma raro y familiar a un tiempo: el italiano. Los aventureros del alma que quisieran, contra viento y huracanes, tener una copia de esta preciosísima aventura filosófica, la podrán encontrar siguiendo estas coordenadas: Su Hegel es un volumen recopilado por Claudio Cesa, para la Collezione di Testi e di Studi de la editorial Il Mulino. Consta de 450 páginas intensas que cuestan $€ 30$ (treinta euros).

Si a Verra no lo conocí, a Giulio Albanese, sí: lo vi más de una vez, platicando de justicia, del Sur del mundo, de las posibles estrategias útiles para resolver la vida de millones de mujeres y hombres que sobreviven en el planeta.

Giulio Albanese, nacido en Roma en 1959, es un misionero comboniano, uno que habla de la miseria porque la conoce y no por presuntuoso. Vivió en África por muchos años, y ahí desa- 
rrolló la dúplice actividad periodística y misionera: por un lado, contar al mundo la realidad de los últimos; por el otro, no dejar de hacer lo que hay que hacer... En Kenia durante algunos años fue director del New People Media Center y de dos periódicos sobre la actualidad africana en lengua inglesa: el New People Feature Service y el New People Magazine.

El libro se llama Soldatini di biombo. La questione dei bambini-soldato (Soldaditos de plomo. La cuestión de los niños soldado), y trata de una plaga social, aquélla de los niños empleados en la guerra: más de trescientos mil menores de edad actualmente, matan y mueren en conflictos militares, y centenares de millares son los que combatieron, en la última década, en ejércitos gubernativos o armadas revolucionarias.

Tampoco esto será un libro de cabecera, lo sé... ¿Quién podría dormir después de haber leído tal escándalo? ¿Quién podría relajarse leyendo acerca de niños transformados en auténticas máquinas de guerra?

Albanese cuenta una serie de historias basadas en el drama de los niños que, en Uganda y Sierra Leona, son utilizados como soldados; dos realidades emblemáticas para todos los que se baten en contra del reclutamiento de los menores. Dos países donde la violencia desoladora del mundo de los adultos no deja esperanzas a una humanidad todavía lampiña, obligada con instrumentos de presión física y psicológica a combatir sin piedad: verdadera 'carne de cañón' al servicio del juego del poder de los adultos.

Secuestrados a la edad de diez, once años, los niños son convencidos de ser invencibles por medio de extraños rituales mágicos de derivación animística y sustancias anfetamínicas. A veces, su ciega violencia es dirigida contra las mismas aldeas donde crecieron, hecho que frustra, al final del conflicto, toda estrategia de reintegración en las familias de origen.

Super Soldier tenía nueve años cuando fue secuestrado en Sierra Leona por los rebeldes del Frente Unido Revolucionario, RUF. Alguien tuvo el atrevimiento de contarle que debía combatir por el bien de sus padres. Lástima que fueron justo aquellos sanguinarios torturadores los que habían destrozado por entero a su familia. Super Soldier intentó huir pero fue capturado. Por castigo, le imprimieron a fuego en el pecho las iniciales del RUF.

Escribe Albanese en la introducción de este libro que no me deja dormir:

'Es inmoral que los adultos quieran hacer combatir a los niños. No hay excusas ni motivos aceptables para armar a los niños'. Leo 
casi por casualidad esta frase de Desmond Tutu, sobre el drama de los niños soldado en octubre de 2003 , mientras me encuentro en el tren directo a Londres: se trata del artículo de un joven redactor en ocasión de no sé cuál cumbre internacional sobre los derechos de la infancia. Las palabras del obispo sudafricano me hacen el efecto de una bomba. No sólo creo que lo que afirma el premio Nobel de la Paz es verdadero, sino tengo también la inspiración para escribir este libro, justo mientras el tren hace lentamente su entrada en Victoria Station.

Desde hace años viajo a través de África, y pasé largos períodos en los frentes de guerra, los frentes olvidados por la gran prensa internacional. Así me vino a la mente el rostro de Super Soldier, un niño encontrado a Kambia, en Sierra Leona, en un día de junio del 2000. Originario de Port Loko, tenía trece años y desde hace cuatro había abrazado, no por su voluntad, un fusil. [...] Super Soldier encontraba el valor para matar gracias a drogas mortales, de las que queman el cerebro. [...] No sé qué fin haya tenido Super Soldier, ahora que en su país ha estallado la paz, pero temo que no se la pase muy bien considerando la miseria que atrapa a Sierra Leona. Siempre me repetía que quería estudiar para ser médico y curar a la gente. Pensando en él, también me acordé de Super Boy, otro soldadito de aquella banda criminal que controló los centros diamantíferos del ex-protectorado británico. Tenía menos de diez años, pelo corto, delgado como un pajarito, llevaba orgullosamente una pistola calibre nueve que, escondida bajo la axila y amarrada a la altura del cinturón, le llegaba casi a la rodilla. Verlo caminar casi daba ternura.

El libro de Giulio Albanese se vuelve adictivo: más me ofende y más lo necesito, es como si necesitara descubrir la realidad de las cosas, como si no me quisiera resignar a la ignorancia. Soldatini di piombo es un libro publicado por Feltrinelli que vale mucho más de lo que cuesta: apenas $€ 8$ para saber lo que pasa en este pequeño e injusto planeta.

Un estudiante de Relaciones Internacionales debería de saber que:

en 1998, algunas acreditadas organizaciones por los derechos humanos se reunieron en la Coalición Internacional en Contra del Empleo de los Niños Soldado y, después de una extraordinaria campaña de presión sobre los gobiernos y la movilización de la opinión pública, el 12 de febrero de 2002 obtuvieron un protocolo opcional de la Convención Internacional sobre los Derechos de la Infancia, que fija en dieciocho años la edad mínima para participar directamente en conflicto bélico.

Lo debería saber todo estudiante de cualquier disciplina, así como 
cada docente decente que camine por los pasillos de una universidad. La ignorancia ya no es un pretexto, a la mejor nunca lo fue; el libro de Giulio Albanese nos quitará el sueño, pero nos dará la posibilidad de estar un poco más informados y, al final, de ser hasta un poco mejores.

En español podemos, sobre el argumento, leer el interesantísimo Niños Soldado del periodista Jimmie Briggs, sobre la utilización de niños soldado. No es un fenómeno nuevo, nos confirma Briggs, pero se ha vuelto mucho más llamativo a raíz de su repercusión. Se trata de un libro de Océano que cuesta $€ 20$.

En Niño Soldado, otro libro, publicado por Martínez Roca ( $€ 17)$, Peter -el autor, que desconoce su edad exacta- narra con profusión de detalles y mucha sinceridad su historia a quienes le atienden en un centro de rehabilitación de la Cruz Roja donde ha aprendido el oficio de carpintero.

Se trataba de ir uno por uno y esconderse tras un arbusto. A continuación los soldados disparaban directamente al arbusto, muchas veces a ras de suelo para asegurarse de que te darían. Se trataba de demostrar que podías salir de allí con vida. Ese día tenía tanto miedo que conseguí salvarme. Pronto, gracias a las drogas, no me daba miedo ir en la primera línea de fuego. Los más pequeños éramos los más valientes.

Mientras leo, me pregunto si vale la pena torturarse con estos escritos, la sensación de impotencia es grande y trata de transformarse en pretexto y justificación. Cómo nos gusta construirnos nuestros personalísimos pretextos...

Sin embargo, el mismo Albanese me contesta desde las páginas de una bella entrevista:

El libro sobre el niño soldado quisiera servir a una causa que apasiona a todos los que creen de veras en una pacífica solución de los conflictos. Se ha hablado mucho en estos años de amnistía, de medidas legales que puedan rehabilitar a los niños soldado para darles un futuro, para liberarlos definitivamente de sus 'pigmaliones' de muerte.

Frente a un niño armado que asesina y tortura, y es torturado y asesinado, uno puede llegar a perder toda esperanza, porque en estas condiciones creer es difícil: creer en una idea, creer en un principio, creer en un Dios... No sé si es verdad que hoy la civilización moderna conoce el fin del cristianismo; tampoco puedo decir si el cristianismo tiene un fin en mí; sin embargo, hay un libro publicado por Feltrinelli, que me parece extraordinariamente actual: se llama $L a$ 
salvezza senza fede (La salvación sin $f e)$ y trata de la transformación del cristianismo en civilización.

El paganismo es evocado como posible modelo: una vida larga, no eterna, una vida buena y una ética de lo 'finito' por una humanidad nueva.

El autor es Salvatore Natoli, nacido el 18 de septiembre de 1942 y docente de Filosofía Teorética en la Segunda Universidad de Milán.

En este libro, Natoli desarrolla una reflexión sobre la posibilidad para el hombre contemporáneo de habitar el mundo sin fugas hacia una improbable trascendencia, y sin inútiles delirios de omnipotencia. La "Ética de lo finito" significa, en efecto, comprenderse a sí mismos a partir de la conciencia de la propia mortalidad.

Sin embargo, también aquella cristiana es una ética de lo finito. No se trata de la limitación natural cuya medida es la muerte, sino de aquella criatural, es decir, la insuficiencia de todo ser para existir per se. Pero Dios crea las cosas de la nada, y si las abandona recaen en aquélla misma nada de donde vienen. Este Dios en el curso de la modernidad mano a mano se ha evaporado [...]. El hombre contemporáneo se encuentra atrapado más que nunca en la antinomia trágica.
Si bien a los griegos no se vuelve, de ellos se empieza nuevamente. Por otro lado, no ser cristianos no quiere decir ser anticristianos: la encarnación puede ser interpretada como una de las formas más altas de recíproca donación. Cada quien puede vivir así bajo la señal de la redención. Hic et nunc.

Esta obra vale verdaderamente la pena: 272 páginas por $€ 10$. Se trata de un esfuerzo accesible, sobre todo tratándose de un tema tan importante. Cuántas veces hemos discutido durante nuestras clases acerca de problemas sobre el verdadero significado de la Ética... Salvatore Natoli nos contesta que:

no existe Ética sin normas, pero éstas se arraigan en algo más originario y profundo, proceden en general de las que llamamos 'visiones del mundo'. La Ética no significa nada diferente de aquél que la palabra misma sugiere: éthos quiere decir costumbre, hábito, y en este sentido la Ética tiene prioritariamente que ver con el habitar, con el modo con que los hombres viven normalmente sobre la Tierra.

De repente me acuerdo que entre mis montañas de hojas debe de haber un libro que me costó más imprimir que comprar en la librería. Se intitula Cuatro filósofos en busca de Dios, un trabajo de investigación y análisis de 
Alfonso López Quintás dirigido a la comprensión del problema extraordinario de la fe. Unamuno, Edith Stein, Romano Guardini y García Morente, cuatro personalidades tan distintas, se interrogan sobre Dios y qué significa creer en Él.

Se afirma actualmente a menudo que creer en un Ser Supremo y vivir conforme a tal fe es una cosa del pasado. A veces no se afirma, pero se da por supuesto. Ya sabemos que uno de los recursos estratégicos de la manipulación consiste en no abordar directamente las cuestiones, no afrontar los problemas, no poner a prueba la propia inteligencia y los propios conocimientos. Es más rentable mantenerse en un nivel de superficialidad y sugerir que no hace falta siquiera entrar en la cuestión. Se indica que hoy es un asunto liquidado y que ninguna persona cabal y civilizada osa ponerlo en duda.

López Quintás quizá tenga razón: la duda es la sal del conocimiento. Pero, ¿cómo olvidar las espléndidas palabras que Bertolt Brecht escribió en 1932 ?

Frente a los irreflexivos, que nunca dudan, están los reflexivos, que nunca actúan.

No dudan para llegar a la decisión, sino para eludirla. Las cabezas sólo las utilizan para sacudirlas. Con aire grave advierten contra el agua a los pasajeros de naves hundiéndose.

[...]

¿De qué le sirve poder dudar a quien no puede decidirse? Puede actuar equivocadamente quien se contiene con razones demasiado escasas, pero quedará inactivo ante el peligro quien necesite demasiadas.

Me gusta este salto del pensamiento, este vuelo pindárico que de la palabra filosófica es capaz de llevarme a la palabra cotidiana; si el problema de la fe y la salvación tiene que ver conmigo, que entonces tenga que ver también con mi vida, mi existencia diaria, mi duro oficio de vivir.

El oficio de vivir, que no pudo soportar el gran Cesare Pavese, no lo pudo soportar tampoco un hombre que dio mucho a Europa, a una idea humanista de la Unión y las batallas por un medio ambiente finalmente respetado y limpio. Ese hombre se llamaba Alexander Langer y, a pesar de que el nombre nos engañe, era italiano.

Alexander Langer había nacido en el 1946 a Sterzing/Vipiteno, en la provincia italiana de Bolzano (Bozen). En los años ochenta figuró entre los promotores del movimien- 
to político de los Verdes en Italia y en 1989 fue diputado del Parlamento Europeo. Líder de la oposición a la primera guerra del Golfo y luego de la facción que exigió y obtuvo una decidida intervención política, humanitaria y, asimismo, de 'policía internacional' en la ex Yugoslavia, Langer fue promotor de resoluciones sobre temas de gran importancia: Kosovo, Chipre, los derechos de los kurdos en Turquía e Irak, el Tibet, las repúblicas bálticas, una política demográfica respetuosa de la ética y de los derechos de los pueblos del Sur, la institución de un tribunal internacional por el medio ambiente, contra la clonación de embriones humanos, etc.

Era un hombre empeñado en jugar siempre y en cualquier condición, y por esta razón representaba un modelo, un paradigma de 'persona política'. Fue, entre muchas cosas, uno de los fundadores del Foro de Verona por la Paz y la Reconciliación en la ex Yugoslavia, la más importante red de enlace entre demócratas de todas las regiones y etnias del área de la ex Yugoslavia, porque estaba convencido que la gente tenía que hablarse y que la palabra era la conditio sine qua non para la recíproca comprensión.

Por esta razón, y en nombre de sus principios democráticos, siempre luchó en contra del muro de goma llamado 'sistema', y un día de 1995, harto y cansado, se dio muerte. Tenía 49 años. Nos sorprendió a todos. Hace 12 años éramos una generación que todavía creía que un cambio era posible y que los héroes, todos jóvenes y bellos, no se rendían nunca. Hace 12 años... Parece una eternidad, y sin embargo los problemas siguen vigentes -acaso más graves- y todos sin respuestas.

Por ello, el libro que nos propone Fabio Levi - publicado siempre por Feltrinelli- se revela como un vehículo indispensable para retomar el discurso bruscamente interrumpido, un instrumento magnífico para acompañar a Alexander Langer en su viaje obstinado hacia la utopía: In viaggio con Alex (De viaje con Alex) es el recuento de un proyecto de vida extraordinariamente rico y complejo, que terminó un día cualquiera, el 3 de julio de 1995, de manera inesperada: con un suicidio.

De Langer, mi generación recuerda sobre todo tres cosas esenciales: pasión, originalidad e independencia.

Una de las grandes dificultades de hoy es encontrar, no sólo buenas razones o causas válidas en qué empeñarse, sino también razones porque este empeño tenga un sentido, no sólo de testimonio o para salvarnos la conciencia. El punto fundamental es justo éste: el reconocimiento de esta dificultad grandísi- 
ma. Hoy en día hay muchos hechos desalentadores y, si uno se fija en las guerras, el hambre, la enorme diferencia que aumenta entre ricos y pobres, podría hasta desanimarse antes de empezar a empeñarse. [...] Pensemos cuánto tiempo necesita un árbol para crecer y en cuán poco tiempo se abate, cuánto tiempo necesitamos para formar nuestras reservas y cuánto se necesitó para que nuestros mares se llenaran y cómo, en muchos casos, hoy ya los hemos vaciado. [...] Si se quiere trabajar en un cambio, hacen falta contextos, personas, comunidades que de algún modo también animen a quien esté cansado de la dictadura de la imagen, es decir que alienten por ejemplo, a quien no es esclavo de la imagen televisiva o de la prensa, sea que se trate de magistrados o de obispos, de deportistas o de médicos. Sabemos que en el momento en que el ejercicio de una función, el de una participación civil o cualquier otra cosa, se desarrolla bajo el condicionamiento del ídolo del teatro; por consiguiente, es casi imposible la verdadera participación y el peso de la gente: la misma verdad estará ausente. ${ }^{1}$

Alexander Langer era un hombre aparentemente fuerte, y sin embargo recordaba el personaje de Steiner en La dolce vita de Fellini: su reflexión

1 "Quando l'economia uccide... bisogna cambiare", 27.1.1995, Centro Ricerca Pace Viterbo-Ponencia. alrededor de la vida lo llevaba con frecuencia a ver cosas horribles que los demás -los distraídos o los prudentes- no veían. Y por esas visiones, Langer-Steiner sufría terriblemente. El oficio de vivir se le hacía pesado, a veces insoportable. En efecto, no soportaba las injusticias en contra de los 'pequeños', los últimos, los débiles:

Uno puede ser pequeño de muchas maneras: falta de dinero o de tarjetas de crédito, de diplomas y de empleo, de pan y de casa, de influencia y de fama, de armas y laboratorios... Y casi todos compiten para volverse grandes, para tener éxito, para ser respetados y temidos, para conquistar el control de los paquetes accionarios, de la fertilidad, de la audiencia, del espacio, de las bolsas, de las mentes. Para ser competitivos hace falta ser grandes, para ser grandes hace falta ser competitivos. [...] Existe un modo particularmente penoso de quedarse pequeños y de no poder crecer: quien usa su voz, su escritura, la comunicación ad personam, la discusión en la comunidad como modo de informar y para confrontarse, hoy sabe que no puede salir de la pequeña dimensión, de la marginalidad. Los grandes, en efecto, parecen tales porque sus megáfonos y sus televisoras difunden su omnipotencia y magnifican su imagen. No es casual que todos los que buscan realizar un golpe de 
estado para volverse grandes traten, en primer lugar, de adueñarse de la comunicación masiva: televisión, radio, prensa, cine, publicidad. $^{2}$

Alex Langer, el incansable, se dio muerte ahorcándose de un árbol de chabacano. "Los pesos se me volvieron insoportables. No sean tristes, continúen con lo que era justo", dejó escrito en un papelito. Lo que era justo, esas palabras...

La Justicia, unos de los problemas de la civilización contemporánea que encontramos dentro y afuera de nuestros salones de clase del ITAM: una justicia que se vuelve política, una modernización de la reflexión que prevalece hoy y que está al día con la evolución del mundo contemporáneo. ¿Cómo olvidar las clases de política que John Rawls impartía regularmente en Harvard en la década de los 80, y que contienen in fieri las ideas para una nueva teoría de una justicia finalmente equitativa?

Rawls -leo en la cuarta de forros del libro publicado por Paidós en 2002- es consciente de que, desde la publicación de la Teoría de la Justicia en 1971, la sociedad se ha alejado aún más del concepto de la justicia como equidad. Sus ideas conservan, empero, todo su vigor y relevancia

2 8.7.1994, Mensaje a la "Cumbre de los pequeños", en ocasión del G7 en Nápoles, "IDOC INTERNAZIONALE". para los debates de una sociedad pluralista en torno al significado y la viabilidad teórica del liberalismo. Este libro demuestra que puede alcanzarse la claridad moral aun cuando el compromiso colectivo con la justicia sea incierto.

Por un lado, las ideas fuertes de Rawls; y por el otro, la difícil relación entre La belleza y los oprimidos, postulada en nueve magníficas lecciones por Salvatore Veca, profesor de Filosofía Política y subdirector del Instituto Universitario de Estudios Superiores de Pavía.

Sin perder la fe en una sociedad mejor, en una utopía razonable para un mundo más justo y más digno de ser habitado, y sin olvidarse de que es necesario tomar en serio al mundo, así como para no caer en el error fatal de la búsqueda perenne de la sociedad perfecta, las nueve lecciones de Veca aceptan el desafío que el proceso imparable de la globalización lanza también al mundo aparentemente abstracto de la filosofía política, imponiendo una reflexión exhaustiva sobre sus propias bases y sus conocimientos.

La bellezza e gli oppressi, de Salvatore Veca, cuesta $€ 13$ y es un libro publicado en Italia por Feltrinelli, mientras Paidós publica en nuestro mundo hispanoparlante La justicia como equidad de John Rawls. 
En resumen, un triángulo de libros extraordinarios: In viaggio con Alex, de Fabio Levi, (Feltrinelli), La bellezza e gli oppressi, de Salvatore Veca (Feltrinelli) y La justicia como equidad, de John Rawls (Paidós).

Cursos, recursos y encuentros ocasionales. Giulio Albanese, Alexander Langer, Veca, Rawls; universos paralelos con un solo lenguaje: la justicia. Langer no soportaría la historia de Super Soldier simplemente porque es inaceptable. La asociaría simplemente al Mal.

El Mal, un tema ordinario que se hace excepcional en el libro homónimo (Il male) de Edoardo Boncinelli.

Leo, en este enésimo encuentro deseable y a pesar de todo indeseado, que ni siquiera existe un mal objetivo, metafísico, ni existe el Mal en naturaleza, entre los animales, que siguen la ley del instinto. Y lo que es definido como mal 'natural', sin culpa porque, originado por factores ambientales, biológicos y genéticos, posee una intrínseca legitimidad. Escribe Boncinelli:

El hombre quedará para siempre como una extraña, híbrida criatura, suspendida entre instinto y razón, entre necesidad y libertad. El mal 'radical', auténticamente irreducible, debemos buscarlo dentro de nosotros, pues allí es donde habitan las contradicciones que animan nuestro ser, en nuestra imperfección, pero que también conforman nuestra enorme riqueza. Como Kant afirma: "De la madera torcida de que está hecho el hombre se puede sacar bien poco de derecho y escuadrado", pero de aquella madera se ha podido extraer mucho, y mucho todavía podrá sacar. Y, dichosamente, también nuestra idea de Mal tiene bien poco de 'derecho y escuadrado'.

¡Que personaje, Edoardo Boncinelli! Un físico, sí, un físico que dirige, en la bella y mitteleuropea Trieste, la Escuela Internacional Superior de Estudios Avanzados (SISSA). Un hombre que después de dirigir por años laboratorios de biología de desarrollo molecular, y el Instituto Internacional de Genética y Biofísica del CNR de Nápoles, y el hospital San Raffaele de Milán, decide finalmente dedicarse a un aspecto de la humanidad que no se mide, no se pesa y no se puede observar en laboratorio: el que llamamos, vulgarmente, el Mal.

No estamos hablando de un científico loco. Si lo prefieren, su locura es de las buenas, de las que enseñan a caminar sobre el hilo, a subir hasta la Luna con una soga infinita, a gritar en contra de los molinos de viento. Miembro del Academia Europea y de la Organización Europea de Biología Molecular y de la Human Genome Organization, Boncinelli ha dedicado toda una vida al estudio de la 
genética y la biología molecular de los animales superiores y del hombre, localizando y nombrando un cierto número de genes que juegan un papel fundamental en el control del desarrollo del cuerpo y en la formación del cerebro. ¿Qué habrá encontrado durante sus investigaciones para decidir que un científico podía hablar del mal absoluto? Tan urgente es este tema que nadie, hoy en día, se siente absuelto...

Boncinelli me sorprende con su razonamiento claro y metódico. El Mal en sus palabras se convierte, con el pasar de las páginas, en el rostro complejo de nuestro sufrimiento. Y sin embargo, me pregunto: ¿Qué es el sufrimiento? ¿Qué son el dolor, la enfermedad?

Un físico trata de explicarnos, en un libro fascinante e incómodo, qué es la conciencia de la propia muerte, cómo metabolizar la pérdida, la violencia, el abuso, la injusticia, la maldad, la envidia, el deseo insatisfecho, el sentido de inadecuación e inutilidad que nos hieren a lo largo de la vida. Si Boncinelli tiene razón, infinito es el espectro de nuestras experiencias que llamamos superficialmente 'mal'.

Desde siempre el Mal acompaña nuestra percepción de la vida, se introduce en mil formas en nuestra existencia, obligándonos tarde o temprano a interrogarnos. ¿Qué es el Mal?
Hannah Arendt hablaba justamente de 'banalidad del Mal', y el escritor italiano Italo Svevo veía hasta en la salud un mal incurable:

Yo estoy analizando la salud de Augusta, pero no lo logro porque me doy cuenta que, analizándola, la convierto en enfermedad. Y escribiendo de ello, empiezo a dudar si aquella salud no necesitaría una cura o una instrucción para aliviarse. ${ }^{3}$

Justo detrás de $A$ rebour de Huysmans, me encuentro un papelito doblado en cuatro, donde, hace unos años garabateé unos versos del gran Eugenio Montale:

A menudo el mal de vivir he encontrado:

Era el río angosto que murmura, Era el arrugarse de la hoja

Seca, era el caballo desplomado.

No supe bien, fuera del prodigio

Que abre la divina indiferencia:

Era la estatua en el sosiego

Del mediodía, y la nube, y el halcón que vuela alto. ${ }^{4}$

La divina indiferencia: todo el Mal del mundo resumido en ocho renglones violentos. ¡Los poetas, qué extrañas criaturas! Leer a un poeta antes de dormir es como renunciar, de modo masoquista, al sueño. cap. 6 .

${ }^{3}$ Italo Svevo, "La conciencia de Zeno",

${ }^{4}$ Eugenio Montale, "Ossi di seppia”, 1925. 